\title{
INTRODUÇÃO A MASTOZOOLOGIA DO BRASIL MERIDIONAL
}

Fernando Dias de Avila-Pires ${ }^{1}$

\section{INTRODUÇÃO}

O extremo meridional do país, ao sul da Capitania de Santo Amaro, que, com a de São Vicente veio a constituir o Estado de São Paulo, não compartilhou do destino das demais, quando da divisðo do Brasil-Colônia em capitanias hereditárias. Durante o reinado português, o território gaúcho ficou subordinado diretamente à Coroa e, lindeiro das possessoes espanholas, constituía zona de importância estratégica para a defesa do território. Segundo Ayres de Casal, a região era, e por aquela razão, designada como "Capitania D'El Rei".

Os primeiros colonizadores europeus partiram da Capitania de São Vicente e estabeleceram-se na região da Lagoa dos Patos, em fins do século XVII. Em 1680, por ordem do Infante Dom Pedro ao Governador do Rio de Janeiro, Dom Manoel Lobo foi encarregado de fundar a Colônica do Sacramento, na margem esquerda do Rio da Prata, com a finalidade de impedir o assentamento de espanhóis na região. Entre Laguna (Santa Catarina) e Colônia (hoje, Uruguai) foi aberto um caminho terrestre destinado a facilitar o transporte e comércio de gado. O litoral do Rio Grande do Sul não oferecia facilidades à navegação costeira e a própria Lagoa dos Patos era conhecida por suas águas agitadas e pela perigosa barra de seu sangradouro. Assim, as estâncias situadas na restinga, entre o mar e as lagoas costeiras, foram interligadas por estrada, o que era excepcional, na época (Ferreira Filho, 1975).

Em 1737 fundou-se o forte de Jesus-Maria-José, à margem do canal sangradouro da Lagoa dos Patos. Em 1742 estabeleceu-se a colônia de imigrantes açorianos de Porto dos Casaes, que daria origem a Porto Alegre. Portugal decidira ocupar o território ao sul de Laguna, localizando, estrategicamente espaçados, núcleos como aquele, constituídos por casais de Ilhéus, tanto da costa (Estreito, Mostardas, Conceição do Arroio - hoje Osório) como no Interior (Viamão, Taquari, Rio Pardo). Em 1751 surgiu a primeira vila, denominada Vila de Rio Grande de São Pedro, no local do antigo forte de Jesus-Maria-José, a partir da qual concederam-se sesmarias até Santa Vitória do Palmar. Em 1760 o Marquês de Pombal criou a Capitania do Rio Grande do Sul, subordi-

Departamento de Zoologia, UFRGS. Bolsista do CNPq. 
nada ao governo do Rio de Janeiro, a qual se tornou autônoma em 1807. Em 1763 surgiu São José do Norte. Em 1777 foi firmado o Tratado de Santo Ildefonso, que determinava a demarcação de fronteiras entre as terras portuguesas e espanholas. O primeiro comissário foi o Brigadeiro Sebastião Xavier da Veiga Cabral, governador de Rio Grande de São Pedro.

Disputas de terras e gado conflagaram o território gaúcho até o século passado. Em 1820, A. de Saint-Hilaire descreveu os acontecimentos recentes, oriundos de pendências com índios e religiosos, de incursão de caudilhos vizinhos, de prepotência do governo que permitia a requisição indiscriminada de bens e serviços dos estancieiros e peớes.

Em 1824 iniciava-se a colonização alemã, a partir do núcleo de São Leopoldo, fundado na região onde terminava a floresta do Caminho do.Sul. As encostas serranas, consideradas mais férteis que as baixadas, receberam levas de famílias germânicas, que se estabeleciam ao longo de "linhas" ou picadas. Informaçбes importantes sobre a fauna de mamíferos, bem como sobre a história natural, a etnologia e a arqueologia do Rio Grande do Sul foram coligidas por médicos e mestres-escola que ali viveram. Hensel (1867) descreveu essas colônias em detalhe. Em Cesar (1969) encontram-se transcritos interessantes relatos dos primeiros cronistas que percorreram a região e um esboço da bibliografia de história e geografia do Rio Grande do Sul foi publicado por Beretta (1976).

Limites políticos e biogeográficos raramente coincidem e, assim, limitei-me a estudar a situação das espécies de mamf́feros descritas das regiøes de serra e pampa, da zona de contato das sub-regiøes Guiano-Brasileira e Pampeana, no Estado do Rio Grande do Sul, Brasil. Esta é a área menos conhecida, atualmente, do ponto de vista mastozoológico, no país.

\section{EXPEDIÇO์ES ZOOLÓGICAS}

Duas expediçбes proporcionaram contribuiçøes importantes para o conhecimento dos mamíferos do Brasil meridional: a de Reinhold Hensel, de Berlim, e a de Herbert $\mathrm{H}$. Smith, de Filadélfia. Uma terceira contribuição de vulto deveu-se a um residente, médico imigrado da Alemanha, Herman von Ihering. Alguns coletores merecem ser mencionados que, não havendo publicado formalmente os resultados de suas observaçóes e pesquisas, contribuíram através da organização de coleçбes e do registro de informaçóes episódicas sobre a ocorrência de espécies e sua distribuição geográfica. Auguste de SaintHilaire, botânico francês que viajou extensamente por todo o sul do Brasil e pelo Uruguai, coletou mamíferos para o Muséum National D'Histoire Naturelle, Paris. Friederich Sellow, também botânico, companheiro de Freyreiss, foi mencionado por Rodolpho Garcia, que comentou: "Dificilmente um estrangeiro poderia penetrar no país com maiores vantagens do que esses dois viajantes, pois eles conheciam sua língua e os seus costumes, e as excursóes 
que vêm realizando já há muitos anos, os prepararam convenientemente para isso." Avé-Lallemand, no relato da visita ds colônias alemđs do Rio Grande do Sul, referiu-se às freqüentes visitas de Sellow a Caçapava do Sul. Chegou Sellow, ao Brasil, em 1814, dedicando-se à coleta de plantas. No ano seguinte aceitou o convite do Príncipe Maximilian zu Wied Neuwied para acompanhá-lo em sua viagem pelo leste brasileiro (Avila-Pires, 1965). Passou a perceber, do governo brasileiro, uma subvenção de 400 mil réis por ano, na qualidade de naturalista pensionário de S. Majestade Imperial. De Caravelas, na Bahia, escreveu a Liechtenstein, entåo diretor do Museu de Berlim, uma carta datada de 15 de dezembro de 1815 , oferecendo seus préstimos, o que lhe valeu um auxílio de $\mathcal{L} 100$ anuais. A partir de 1817 iniciou as remessas de material para a Alemanha. Regressando ao Rio de Janeiro, entrou em contato com Ignaz von Olfers, então conselheiro da Legação da Prússia (e que, a partir de 1839 iria assumir a direção dos Museus Reais de Berlim, cargo que ocuparia por 30 anos). A contribuiçฐ̃o do Olfers a um livro do Barão de Eschwege constituıu fato de grande importância para a mastozoologia neotropical, ressaltado por Hershkovitz (1959). De agosto de 1818 a maio de 1819, Sellow e Olfers viajaram por Minas Gerais e São Paulo. Separaram-se em Ipanema (hoje, município de Iperó), onde Sellow encontrou-se com Saint-Hilaire. A fazenda Ipanema tornou-se célebre pelas coletas de Natterer e de outros naturalistas que a visitaram no século XIX. Daquela viagem, regressou Sellow ao Rio de Janeiro em 1820. Em fins de 1821 seguiu para o sul em companhia de Petẹr Clausen, o mesmo que indicaria, anos mais tarde, a seu compatriota Peter W. Lund, a existência das ossadas de mamíferos nas cavernas fossiliferas de Minas Geraiș. Sellow coletou em Santa Catarina, Rio Grande do Sul (Missбes) e Uruguai, regressando em 1828. Após curta permanência no Rio de Janeiro, retornou ao sul. Entre 1829 e 1830 esteve em São Paulo e Minas Gerais. Em outubro de 1831 morreu afogado na Cachoeira Escura, Rio Doce. Na região do Rio Uruguai, Sellow coletou um roedor, que foi denominado por Brants, em 1827, Mus vulpinus, o primeiro mamífero a ser formalmente descrito do Rio Grande do Sul. Dois anos mais tarde, Lichtenstein descreveria um tuco-tuco, Mus torquatus. [Vide Urban (1893), Klinge (1941) e Stresemann (1948)].

Entre o período de imigração alemã promovida pelo governo central e aquela iniciada sob os auspícios do governo provincial, muitos colonos venderam suas terras e seguiram adiante, desmatando as encostas serranas. Um dos imigrantes, engenheiro e oficial, que foi prisioneiro dos índios Coroado por dois anos, Alphonse Mabilbe, "deixou, em 1848, um tratado de História Natural e muitas notas sobre as plantas do Brasil." (League, 1980; Mabilbe, 1983). A ausência de mercado consumidor para os produtos agrícolas da região constituía um dos maiores problemas para o desenvolvimento econômico, fato ressaltado, ainda em 1912, por Roquette-Pinto e notado por ocasião de sua visita ao Rio Grande do Sul, em 1906. No século passado, sesmarias florestais foram sendo desmembradas e colônias particulares desenvolveram- 
se. Uma delas chamou-se Colônia do Mundo Novo e situava-se na zona do alto Rio dos Sinos, às margens do Rio Santa Maria. Três Coroas é a antiga Mundo Novo, hoje cidade e sede de município, desde 1959, desmembrado do de Taquara. Em 1814 foi concedida sesmaria a Antonio Borges de Almeida; pertencia a Santo Antonio e era conhecida como Bom Jesus da Taquara do Mundo Novo. Em 1847, quando se abriu o caminho de Mundo Novo à serra, chegando a Lagoa Vermelha, a regiáo pertencia a Tristão Monteiro que, desde então começou a vender suas terras, denominando a nova colônia Mundo Novo. Em 1887 Taquara foi elevada a vila e, em 1908, a cidade. Hermann von Ihering residiu em Taquara, que se tornou localidade tipo de várias espécies. Também ali morou G. Schneider, que vendeu uma coleção de mamíferos ao British Museum, a mesma que fôra estudada por Leche. Alguns exemplos encontramse em Berlim.

Um professor alemão das escolas públicas da "Linha Solentária", Theodor Bischoff, interessava-se por arqueologia (Brochado, 1969) e, segundo Ihering (1892) "com especial interesse e grande sucesso, dedicou-se ao estudo dos nossos mamíferos." Reinboldt (1983) chama a atenção, aliás, para o papel do desempenhado na Europa, por gente como ele, dizendo que "são, há séculos, as casas dos pastores e mestre-escolas que, nos campos e nas pequenas cidades das províncias, formavam os núcleos de cultura." Von Ihering mencionou, também, a contribuição de L. Morsch, de Passo Fundo, que the forneceu material zoológico, além de informaçб̃es sobre espécies da região. Também em Passo Fundo coletou José Barbieux, cujo material, datado de 19251931 encontra-se em Munique. Referiu-se Ihering ao "Professor Chr. Enslen", da Colônia de São Lourenço, a quem Lima dedicaria, mais tarde, uma nova espécie de morcego.

Até então, nenhum trabalho de vulto e de conjunto fôra feito na região. Buscavam os naturalistas viajantes a Amazônia ou os distritos auríferos e diamantíferos das Minas Gerais. O Rio Grande do Sul, com sua costa desabrigada e a barra do canal de Rio Grande de difícil acesso, não atraía muito os zoólogos. Por outro lado, Maldonado tornara-se a meca dos naturalistas que demandavam as terras meridionais.

A primeira expedição de importância maior, no estado, foi a de Reinhold Hensel, que permaneceu no Brasil entre 1863 e 1965. Descreveu ele as colônias alemãs, sua economia, demografia e situação. Em 1873 surgiu sua contribuição ao conhecimento dos mamíferos, sob a forma de um catálogo descritivo que incluiu as espécies domésticas introduzidas. Considerando o crânio como sendo de importância primordial para o reconhecimento das espécies, reuniu séries de exemplares que lhe permitiram o estudo da variação individual, etária e sexual. Isso constituía novidade em sua época, uma vez que, somente após a publicação da "Origem das Espécies", de Darwin, a análise da variação passou a ser encarada seriamente pelos zoólogos e a merecer a atenção dos taxonomistas. Wallace (1889) dedicou um longo capítulo ab assunto, ressaltando o fato de terem as coleçð̃es zoológicas mudado de feição, 
passando a abrigar séries de indivíduos, de maneira a permitirem o estudo da variação intraespecífica. Preocupou-se Wallace em descobrir maneiras de representá-la graficamente, de modo a facilitar comparaçoes. Nos Estados Unidos, Allen (1876) já demonstrava preocupação com esse fato e suas implicaçбes para a sistemática e para a organização das coleçбes de museus. Hensel propôs a padronização das medidas cranianas, tomando-as com bastante precisão. Deu maior importância ao comprimento basilar e elegeu um "crânio normal" para representar cada sexo. Considerou que uma amostra seria representativa de uma espécie quando contivesse todas as medidas de uma moda. Discutiu a estimativa da idade pela observação das suturas e a seqüência em que elas se soldam. O material de Hensel encontra-se depositado no Museum für Naturkunde (Zoologisches Museum), em Berlim. Segundo informaçб̄es do Prof. R. Angermann (1981, in litt.), os exemplares foram enviados originalmente para o Setor de Anatomia Comparada da Faculdade de Medicina, supondo-se que alguns poucos houvessem sido mandados ao museu. Hensel listou, em 1873, 89 espécies de mamíferos, incluindo espécies domésticas, no que se constitui no primeiro catálogo sistemático da mastofauna do Rio Grande do Sul. Destas, sete eram novas.

Herbert H. Smith (1851-1919) veio ao Brasil, pela primeira vez, em 1870, ainda estudante, integrando a Expedição Morgan, liderada por Charles F. Hartt, seu professor da Universidade de Cornell, Estados Unidos. Freqüentou a universidade entre 1868 e $1872 \mathrm{e}$, em sua viagem inaugural permaneceu no Pará por quatro meses. Hartt fixou-se no Brasil, onde foi encarregado de organizar a Comissão Geológica do Império (1875-1877).

Em 1874, Smith regressou ao Brasil com o intuito de coletar espécimes e estudar a fauna, flora e geologia da Amazônia. Após dois anos de exploração nos arredores de Santarém foi convidado por Hartt, então na chefia da Comissáo Geológica, a explorar os afluentes da margem norte do Rio Amazonas e o Tapajós, tarefa que o ocupou por mais de um ano. Em seguida viajou para o Rio de Janeiro e ali permaneceu durante quatro meses, antes de regressar aos Estados Unidos, em 1877.

No ano seguinte retornou ao Brasil, visitando a Amazônia, o Rio de Janeiro (região da antiga Entre-Rios, hoje Três Rios), Pernambuco e Ceará, estudando os sistemas de transporte, as indústrias cafeeira e açucareira, a vida social, o comércio, a seca e a fome. Para isso fôra comissionado pela Editora Scribner's de Nova Iorque e teve, como companheiro de viagem, o desenhista J. Wells Champney. De suas exploraçб̄es e observaçбes resultaram seis artigos, publicados na revista Scribner's Monthly Magazine, os quais refundidos e acrescidos de notas e de dados colhidos nas viagens anteriores e em leituras de extensa bibliografia brasiliana pretérita e contemporânea, foram editados em livro, publicado em 1879. A descrição da grande seca que assolava então o Ceará e outros estados do Nordeste tem muito de atual e merece ser relida.

Em maio de 1881 partiu, pela derradeira vez, com destino ao Brasil. Após alguns meses no Pará seguiu para o Rio de Janeiro, onde viveu durante 
seis meses e de onde viajou para o Rio Grande do Sul, na chefia da Brazilian Exploring Expedition. Após seis meses de residência em Montenegro prosseguiu para Mato Grosso. Em Chapada, próximo de Cuiabá, permaneceu os quatro anos seguintes. Em 6 de setembro de 1886 regressou aos Estados Unidos e no dia 22 de março de 1919, caminhando para o museu, da cidade onde residia no Alabama, foi morto por um trem de carga, possivelmente devido à incipiente surdez que sempre o afligiu. No Brasil, escreveu para a Gazeta de Notícias e para o Jornal do Comércio. Seus dois compatriotas famosos, Hartt e 0 . Derby também tiveram morte trágica, o primeiro vitimado pela febre amarela e o segundo suicidando-se. $\mathrm{O}$ relato da viagem ao Rio Grande do Sul apareceu, em três partes, no American Naturalist que publicou, também, as descriçбes de Cope das 29 espécies de mamfferos coletados em Montenegro. $\mathrm{Na}$ época em que Porto Alegre tinha cerca de 35000 habitantes, Smith estabeleceu residência em São Jođo de Montenegro, às margens do Rio Caí. A região era coberta por florestas densas, mais ralas nas baixadas e densas nas encostas da serra. Nos locais de solo arenoso e baixo e acima dos limites das enchentes, encontrava-se o fachinal, caracterizado por flora distinta da das encostas e da planície aluvial, esta recoberta de vegetação baixa e campestre. Para o norte estendia-se a floresta contínua e, cerca de $4,5 \mathrm{~km}$ a sudeste, iniciavam-se os campos abertos. Suas excursóes levaram-no até o riacho Maratá, afluente do Rio Caí, cerca de $12 \mathrm{~km}$ de Montenegro. H. Smith coletou cerca de 450 exemplares de mamíferos de 65 espécies distintas, que se encontram depositados nas coleçoes da Philadelphia Academy of Sciences e do American Museum of Natural History. Sua última viagem pelo Brasil foi relatada em 27 artigos publicados na Gazeta de Noticias, Rio de Janeiro, entre 21 de julho de 1886 e 20 de outubro de 1887. Posteriormente eles foram reunidos em livro. No prefácio, Capistrano de Abreu comenta: "Quando a sciencia da distribuição geographica dos animaes vier a ser estudada mais cuidadosamente, a região das florestas da serra do Mar será conhecida como uma sub província zoológica, resto talvez de alguma zona maior, que sumiu do Oceano." Esta unidade zoogeográfica receberia de Mello Leitão, mais tarde, o nome de Província Tupi.

Hermann Friedrich Albrecht von Ihering (1850-1930) nasceu em Giessen e doutorou-se em Erlangen em 1876. Em 1880 chegou ao Rio de Janeiro, em viagem de núpcias, indo residir na Tijuca. Preferindo um clima mais ameno, seguiu o conselho de Lund que, em carta, aconselhara-o a mudar-se para o Rio Grande do Sul. Adquiriu uma chácara em Taquara do Mundo Novo. Após a morte de um filho, vendeu a propriedade e transferiu-se para uma ilha, na foz do Rio Camaqua, nas proximidades de Sáo Lourença, onde permaneceu até 1891, quando partiu com a família para Sáo Paulo. Interessou-se pelo estudo da arqueologia, da etnologia, da colonização alemã e da história natural da região. Suas simpatias políticas tornaram sua permanência difícil no sul após a revolução de 1892-1895. Ihering foi naturalista-viajante do Museu Nacional em 1883, confirmado em 1889 e exonerado em 1891. Convidado 
a integrar a "Commissão Geographica e Geologica do Estado de São Paulo", foi aproveitado pelo então diretor, Orville A. Derby, para chefiar e organizar a Seção de Zoologia do Museu Paulista, anexo à Comissão. (Sobre Derby, veja-se Gonsalvez, 1952). Em 1894, Thering assumiu a direção do Museu e, no ano seguinte, inaugurou as exposiçбes públicas. Em 1896 surgiu o primeiro tomo da Revista do Museu Paulista. Em 1916 Ihering deixou a direção do museu, para fundar outro, em Santa Catarina, o que não chegou a concretizar por falta de verbas adequadas. Partiu para a Argentina e, de lá para a Alemanha. Enquanto residiu no Rio Grande do Sul publicou numerosos artigós e reuniu importante coleção de mamíferos, que vendeu ao Museu Britânico. Em 1892 publicou uma lista comentada das espécies e, durante sua permanência em São Paulo, escreveu sobre marsupiais, carnívoros e primatas, corrigindo e acrescentando dados sobre a fauna do território gaúcho. Muitos de seus exemplares foram descritos por Thomas, em Londres e por Leche, em Estocolmo.

Ihering dedicou-se, desde cedo, aos estudos de distribuição geográfica e foi o primeiro a tentar identificar limites e barreiras no Rio Grande do Sul. Suas idéias foram resumidas em "As Árvores do Rio Grande do Sul" e nos "Mamíferos do Rio Grande do Sul", merecendo serem transcritas:

"Quanto à distribuição geographica dos mammiferos reporto-me às observaçס̄es que fiz no meu trabalho sobre As Árvores do Rio Grande do Sul (pág. 165-166, Annuario do Dr. Graciano de Azambuja para 1892).

A linha do Cebus, como o nosso mappa o explica, não alcança o $30^{\circ}$ parallelo de Lat. S. Mammiferos que não vivem ao sul desta linha são os Micos (Cebus) e os generos Phyllomys, Dactylomys, Sciurus, Lepus. Mais para o sul extende-se a distribuição dos Bugios, que existem na Serra do Herval, mas para os quaes como para a maioria dos outros mammiferos nada consta de certo sobre os seus limites nas margens do rio Uruguay e dos seus afluentes. É preciso estudar ainda a direção da linha do Mycetes, i.é, do Bugio, como tambem da linha seguinte, a da Pacca, em relação às regióes central e occidental do Estado.

A linha da Pacca que quasi se estende até o $32^{\circ}$ Lat. S. inclue a Serra dos Taipes com a florescente Colonia de S. Lourenço. É este o limite meridional da matta-virgem da região brazileira e é sem duvida por isso que alguns mammiferos tambem tem ahi o seu limite meridional. Nestas condiçбes estão a Pacca, a Cotia, a Anta e provavelmente outros sobre os quaes nada consta de certo actualmente, visto que não temos informaçбes exactas sobre os mammiferos do Estado Oriental. E certo, no entretanto, que grande parte de mammiferos brasileiros vivem ainda no Estado Oriental, sem passar o rio Uruguay. Ao contrario o Viscacha (Lagostomus trichodactylus), commum na margem direta do rio Uruguay, falta no Estado Oriental e no Rio Grande do Sul. 
E pois evidente que o rio Uruguay representa outra linha divisora das faunas, linha que chamei do Myrmecophaga (Tamanduá). 0 que se refere aos Tamanduás applica-se tambem aos Coatis e Mão-pellada. $\mathrm{O}$ rio Uruguay é pois na sua parte inferior uma linha divisoria e só na provincia de Corrientes (da Rep. Argentin.) as diversas linhas de que fallei passam do Rio Grande do Sul pelo rio Uruguay de um modo sobre o qual nada consta por enquanto de determinado." Sobre Ihering, veja-se Anon., 1931 e Ihering, R.V., 1920.

Em 1925, Rudolf Gliesch, então "lente de zoologia e Chefe do Laboratorio e Museu Zoologico do Instituto Borges de Medeiros de Porto Alegre" publicava um pequeno volume sobre "A Fauna de Torres". Aquele Instituto daria origem às escolas de Engenharia, Agronomia e Veterinária da universidade do Estado, hoje Universidade Federal do Rio Grande do Sul. As observaçбes, segundo Gliesch, foram realizadas por ocasiðo de quatro visitas realizadas em épocas de veraneio, estando mencionados os anos de 1919, $1924 \mathrm{e}$ 1925. Poucas são as referências a mamíferos, uma vez que o autor preocupou-se em oferecer um manual ou guia da fauna litorânea-aquática. Descreveu a região, que já fôra objeto de observaçбes minuciosas de Roquette-Pinto (1912), e seus dados incluídos na obra do Padre Rambo (1942, 1956). Uma relação de espécies deveria aparecer na revista Egatéa, editada pelo Instituto, o que não aconteceu.

De Torres disse: "Neste lugar, por traz da Torre Sul, da Guarita e da Torre do Centro, vive no solo o tuco-tuco (Ctenomys brasiliensis) que cava ahi suas galerias subterraneas". Esse tuco-tuco devia ser, na verdade, C. minutus. Gliesch mencionou a presença de Noctilio leporinus no Mampituba. Três espécies de cetáceos: o boto "Tursiops tursio", com 10 pés de comprimento e 22 dentes em cada ramo da maxila; o golfinho "Sotalia brasiliensis?" com mais de $2 \mathrm{~m}$ e 40 dentes, como sendo o mais comum; e a toninha "(Stenodelphys branvillei)" com $1 \mathrm{~m}$ e 52 dentes. Informou que a toninha nunca fôra vista entrando na foz do Rio Mampituba.

Na Ilha dos Lobos, observou "Otaria jubata", o leđo marinho e o lobo, "Arctocephalus falklandicus", que Nehring descrevera de Tramandaí como espécie nova.

Mencionou as baleias, de que os pescadores reconheciam três espécies: de gomo, lisa e pintada.

A fase moderna de expediçoes foi iniciada pelo Museu Riograndense de Ciências Naturais, que reuniu as coleçбes remanescentes do Museu Julio de Castilhos e de outras coleçðes públicas e privadas, já na década de 1950 . Em 20 de dezembro de 1972 foi criada a Fundação Zoobotânica do Rio Grande do Sul. Em março de 1974 iniciou suas atividades, incorporando o Parque Zoológico de Sapucaia do Sul, o Jardim Botânico e o Museu Riograndense de Ciências Naturais, que passou a denominar-se Museu de Ciências Naturais. 


\section{Mamíferos descritos do Rio Grande do Sul}

Encontram-se relacionadas aqui as espécies descritas de localidades situadas no Estado do Rio Grande do Sul. Devido à escassez de material em coleçбes e de estudos de caráter regional recentes, muitas delas foram sinonimizadas sem maiores cuidados, pelo critério de proximidade geográfica. Somente a coleta de topótipos e a aplicação de modernas técnicas de análise, à luz dos atuais conceitos de sistemática poderá esclarecer sua situaçáo real. A posição atual de cada uma será discutida no próximo trabalho, em preparação.

\section{Marsupialia}

\section{Famflia Didelphidae}

Micoureus cahyensis Matschie, 1917:288. Localidade tipo: Rio Cahy. Didelphis (Peramys) iheringi Thomas, 1888: 159. Localidade tipo: Taquara. Didelphis (Peramys) henseli Thomas, 1888:159. Localidade tipo: Taquara. Microdelphis sorex Hensel, 1873:122. Localidade tipo: Rio Grande do Sul. Marmosa microtarsus guahybae Tate, 1931: 10. Localidade tipo: Ilha Guahyba, Porto Alegre.

Lutreolina crassicaudata lutrilla Thomas, 1923:585. Localidade tipo: Sao Lourenço.

Didelphis lechei Ihering, 1892:98. Localidade tipo: Sul do Rio Grande do Sul. Didelphis kozeritzi Ihering, 1892:99. Localidade tipo: Rio Grande do Sul.

\section{Chiroptera}

\section{Familia Vespertilionidae}

Vesperugo arge Cope, 1889:136. Localidade tipo: São Jođo /do Montenegro/. Lasiurus ensleni Lima, 1926: 73. Localidade tipo: São Lourenço.

Lasiurus borealis frantzii Peters, 1870:908. Localidade tipo: São Lourenço (fide Cabrera, 1957:112).

\section{Edentata}

Famúlia Dasypodidae

Tatusia platycerus Hensel, 1873:105. Localidade tipo: Rio Grande do Sul. 


\section{Carnivora}

\section{Família Canidae}

Pseudalopex gymnocercus attenuatus Kraglievich, 1930:54. Localidade tipo: ??

Canis thous riograndensis Ihering, 1911:217. Localidade tipo: São Lourenço.

Família Mustelidae

Tayra barbara kriegi Krumbiegel, 1942:94. Localidade tipo: Passo Fundo.

Famflia Felidae

Felis guttula Hensel, 1873:73. Localidade tipo: Rio Grande do Sul.

\section{Famflia Otariidae}

Arctocephalus gracilis Nehring, 1887:92. Localidade tipo: Tramandaí.

Artiodactyla

Família Tayassuidae

Dicotyles labiatus rufa Ihering, 1911. Localidade tipo: Serra Geral.

Famflia Cervidae

Mazama simplicicornis var. kozeritzi Miranda Ribeiro, 1919, pl. 8-10. Localidade tipo: Rio Grande do Sul.

Rodentia

Família Cricetidae

Hesperomys laticeps var. intermedia Leche, 1886:693. Localidade tipo: Taquara.

Hesperomys ratticeps Hensel, 1873:36, figs. 15 e 25. Localidade tipo: Rio Grande do Sul.

Hesperomys dorsalis Hensel, 1873:42, figs. 16 e 26. Localidade tipo: Rio Grande do Sul.

Thomasomys oenax Thomas, 1928: 154. Localidade tipo: São Lourenço. Acodon dorsalis lechei Trouessart, 1904:434. Localidade tipo: Taquara. 
Oxymycterus iheringi Thomas, 1896:308. Localidade tipo: Taquara.

Hesperomys subterraneus var. henseli Leche, 1886:697. Localidade tipo: Mundo Novo.

Mus vulpinus Brants, 1827:137. Localidade tipo: Rio Uruguay (fide Hershkovitz, 1955).

\section{Famı́lia Echimyidae}

Phyllomys dasythrix Hensel, 1873:49, figs. 11 e 12. Localidade tipo: Rio Grande do Sul.

\section{Famflia Ctenomyidae}

Ctenomys torquatus Lichtenstein, 1829, pl. 31. Localidade tipo: "Südlischen Provinzen Brasiliens und die Ufer des Uruguay..."

Ctenomys minutus Nehring, 1887:47. Localidade tipo: "Campos, welche sich östlich von Mundo Novo ... in der Nahe der Meeresküste finden".

Ctenomys flamarioni Travi, 1981:1. Localidade tipo: Estaçáo Ecológica do Taim, Santa Vitória do Palmar.

\section{Familia Caviidae}

Cavia magna Ximénez, 1980. Localidade tipo: Riacho Imbé, Tramandaí.

\section{Famflia Erethizontidae}

Sphigurus sericeus Cope, 1889:136. Localidade tipo: Såo João do Montenegro.

\section{APENDICE}

Duas espécies, descritas por Cope, tiveram as etiquetas dos tipos perdidas. $\mathrm{Na}$ própria descrição original este fato está mencionado. Podem ser de São João do Montenegro, R.S., ou de Chapada, Mato Grosso. São elas:

Felis braccata Cope, 1889:144. Cabrera (1957) dá como sendo Chapada, sem justificar sua opinião.

Myrmecophaga bivitatta straminea Cope, 1889:132.

\section{REFERENCIAS}

Allen, J.A., 1876. On geographical variation among North American mammals. Bull. U.S. Geogr. Surv., 2: 314, Washington, D.C.

Anôn., 1931. Prof. Dr. Hermann von Ihering (1850-1830). Revta Mus. Paulista, 17(1): 553-566, S. Paulo. 
Avé-Lallemant, R., 1953. Viagem pelo Sul do Brasil no Ano de 1858. Primeira parte. Inst. Nac. Livro, R. Janeiro.

Avilla-Pires, F.D., 1965. Type specimens of Brazilian mammals collected by Prince Maximilian zu Wied. Amer. Mus. Novitates, 2209: 1-21, N. York.

Brants. A., 1827. Het Geslacht der Muizen. Berlin.

Brochado, J.J.J.P., 1969. Histórico das pesquisas arqueológicas no Estado do Rio Grande do Sul. Iheringia, Antropologia, 1: 3-42, P. Alegre.

Casal, A., 1976. Corografia Brasilica. EDUSP \& Livr. Itatiaia, S. Paulo.

Cope, E.D., 1889. On the mammals obtained by the Naturalist Exploring Expedition to Southern Brasil. Amer. Natur., 1889 (Feb.): 128-150.

César, G., 1969. Primeiro cronistas do Rio Grande do Sul. 1605-1801. Fac. Filos. Univ. Fed. R.G. Sul, P. Alegre.

Ferreira Fo, A., 1975. História Geral do Rio Grande do Sul. Globo, P. Alegre.

Garcia, R., 1930. Notas. In Anôn., s/d., Diálogos das Grandezas do Brasil. Acad. Brasil. /de Letras/, R. Janeiro.

Gliesch, R., 1925. A Fauna de Torres. Esc. Engenharia, P. Alegre.

Gonsalvez, A.D., 1952 (coord.). Orville A. Derby's Studies on the Paleontology of Brazil. R. Janeiro.

Hensel, R., 1867. Beiträge zur naheren Kenntniss der brasilianischen Provinz São Pedro do Rio Grande do Sul. Zeitschr. Gesell. Erdk., 2: 227-376, Berlin.

Hensel, R., 1873. Beiträge zur Kenntniss der Såugethiere Süd-Brasiliens. Abhandl. Konigl. Ak. Wissensch. Berlin, 1872: 1-130.

Hershkovitz, P., 1955. South American marsh rats, genus Holochilus, with a summary of sigmodont rodents. Fieldiana, Zoology, 37: 639-673, Chicago.

Hershkovitz, P., 1959. Nomenclature and taxonomy of the Neotropical mammals described by Olfers, 1818. Jour. Mammal., 40(3): 337-353, Baltimore.

Ihering, H.v., 1892. As Árvores do Rio Grande do Sul. In Annuario da Provincia do Rio Grande do Sul do Dr. Graciano de Azambuja para 1892. P. Alegre.

Ihering, H.v., 1893. Mamiferos do Rio Grande do Sul. In Annuario da Provincia do Rio Grande do Sul do Dr. Graciano de Azambuja para 1893: 96-124. P. Alegre. Reed. Rev. Arch. Publ. R. G. Sul, 1927, 19: 41-77. P. Alegre.

Ihering, H.v., 1911. Mamíferos do Brasil Meridional. I. Carnívoros, Revta. Mus. Paulista, 8, S. Paulo.

Ihering, H.v., 1914. Os bugios do genero Alouatta. Revta. Mus. Paulista, 9: 231-256. S. Paulo.

Ihering, H.v., 1914. Os gambás do Brasil. Revta. Mus. Paulista, 9: 338-347. S. Paulo.

Ihering, R.v., 1920. O naturalista Hermann von Ihering no Rio Grande do Sul /.../. Alman. Agric. Brasil., 9: 131-135. S. Paulo.

Klinger, B., 1941. Excursão geológica de Frederico Sellow ao Rio Grande do Sul e ao Uruguai (1821-1827). Bol. Centro Rio-Grandense Est. Histor., 2: 35-98, R. Grande.

Krumbiegel, J. Mammals of the Prof. Krieg's South American Expedition. Zool. Anz., $139(5 / 6)$.

League, M.M., 1980. Vida e obra do tenente-coronel-engenheiro Alphonse Mabilde (1806-1892). In T.L. Müller, org., Imigração e Colonização Alemã. Esc. Sup. Teol. S. Lourenço de Brindes, P. Alegre.

Leche, W., 1827. Ueber einige Südbrasilianische Hesperomys Arten. Zool. Jahrb, 1886, 1: 687-701, Jena.

Lichtenstein, H., 1829. Darsterllung neuer oder wenig bekannter Săgethiere. 1827-1834, Berlin.

Lima, J.L., 1926. Os morcegos da coleção do Museu Paulista. Revta. Mus. Paulista, 14: 41-127, S. Paulo.

Mabilde, P.F.A.B., 1983. Apontamentos sobre os Indígenas Selvagens da Nação dos Coroados dos Matos da Província do Rio Grande do Sul. IBRASA/Pró-Memória/ I.N.L., Brasília, D.F. 
Matschie, P., 1917. Einige neue Formen des Didelphis lanigera Gruppe. Sitzungsb. Gesell. Naturf. Fr., Berlin, 1917: 288-290.

Miranda-Ribeiro, A., 1919. Os veados do Brasil segundo as collecções Rondon e de varios museus nacionaes e estrangeiros. Revta. Mus. Paulista, 11: 213-307, S. Paulo.

Nehring, A., 1887. Ueber eine Ctenomys Art aus Rio Grande do Sul. Sitzungsb. Gesell. Naturf. Fr., Berlin, 1887: 45-47.

Nehring, A., 1887. Ueber eine Pelzrobben Arrt aus der Küste Süd-Brasiliens. Arch. Naturg, 1: 75-95.

Olfers, I.v., 1818. Bemerkungen zu Illiger's Ueberblik der Saugethiere nach ihrer Vertheilung über die Welttheile, rücksichtlich der südamericanischen Arten (Species). Abhandl. X, W.L. Eschwege, J. Brasilien, 15 (2): 192-237, Weimar.

Peters, W., 1870. Eine monographische Uebersicht der Chiropterengatungen Nycteris und Atalapha. Monatsb. K. Ak. Wiss. Berlin, 1870: 900-914.

Réclus, E., 1899. Estados Unidos do Brasil. Geographia, Ethnographia, Estatiscica. Garnier, R. Janeiro \& Paris.

Reinholdt, H., 1983. A vida de Jaco Berzelius. Ci. Cult., 35 (9): 1347-1367, S. Paulo.

Rambo, B., 1956. A Fisionomia do Rio Grande do Sul, 1. Selba, P. Alegre.

Roquette-Pinto, E., 1912. Relatório de Excursão ao litoral e a região das lagoas do Rio Grande do Sul (1906). J. Janeiro.

Saint-Hilaire, A., 1974. Viagem ao Rio Grande do Sul. (1820-1821). EDUSP/Itatiaia, S. Paulo.

Schwartzmann, S., 1979. Formação da Comunidade Científica no Brasil. Edit. Nac., R. Janeiro.

Smith, H., 1883. The Naturalist-Brazilian Expedition. Amer. Natur., 17 (4): 351-358; 17 (7): 707-716.

Smith, H., 1884. The Naturalist-Brazilian Expedition. Amer. Natur., 18 (5): 464-470.

Smith, H., 1922. Do Rio de Janeiro a Cuyabá. Melhoramentos, S. Paulo.

Stressmann, E., 1948. Der Naturforscher Friedrich Sellow und sein Beitrag zur Kenntnis Brasiliens. Zool. Jahrb. (Syste.) 77: 401-488.

Tate, G.H.H., 1931. Brief diagnoses of twenty-six apparently news forms of Marmosa (Marsupialia) from South America. Amer. Mus. Novitates, 493: 1-14, N. York.

Thomas, O., 1888. Diagnoses of four new spicies of Didelphys. Ann. Mag. Nat. Hist. (6): 158-159, Londres.

Thomas, O., 1928. A new Thomasomys from Rio Grande do Sul. Ann. Mag. Nat. Hist. (10): 154-155, Londres.

Travi, V.H., 1982. Nota prévia sobre nova espécie de gênero Ctenomys Blainville, 1826 (Rodentia-Ctenomyidae). Iheringia, zool., 60: 123-124, P. Alegre.

Wallace, A. R., 1889. Darwinism. Macmillan, 2a. ed., Londres \& N. York.

Ximénez, A., 1980. Nota sobre el género Cavia Pallas con la descripción de Cavia magnu sp.n. (Mammalia-Caviidae). Rev. Nordest. Biol. 3:145-179, J. Pessoa.

\section{AGRADECIMENTOS}

Ao Dr. A: Angermann do Museum für Naturkunde, Berlim, pelas informaçбes a respeito do material coletado por Hensel. Ao Dr. Ralph M. Wetzel pelo empenho em listar material procedente do Rio Grande do Sul em museus europeus, por minha solicitação. Ao Dr. Ian Bishop, pelas informaçб̃es a respeito dos exemplares prócedentes do Brasil meridional na coleção 
do British Museum (Natural History). A Ruth Hildebrand, pela tradução cuidadosa dos trabalhos de Hensel. A Jocélia Grazia, pela leitura e comentários sobre o manuscrito.

A todos, e ao $\mathrm{CNPq}$, agradecemos por haverem tornado possível a realização do presente estudo. 